\title{
Does the "Office Nurse" Level of Training Matter in the Family Medicine Office?
}

\author{
Rodney A. Erickson, MD, Richard A. Erickson, MS, Paul V. Targonski, MD, PhD, \\ Stephen B. Cox, PhD, James R. Deming, MD, and James W. Mold, MD, PhD
}

Background: The "office nurse" or clinical associate (registered nurse [RN], licensed practical nurse[LPN], or medical assistant [MA]) is a key member of the family medicine care team, but little is known about the influence of their level of training on team performance.

Methods: The performance of the clinical dyad (clinician and associate) was studied in relation to the level of training of the nurse. The dyad's performance was measured by the performance indicators of diabetes scores, patient satisfaction, and productivity.

Results: Dyads with a RN scored higher in meeting all 5 of the diabetes quality indicators $(27.8 \%)$ than those with a LPN (19.3\%) or an MA (14.7\%). For patient satisfaction, the RN dyads also scored higher than the other dyad groups (positive responses: RN, 96.8\%; LPN, 95.5\%; MA, 94.6\%). Productivity was the same in all groups. Better diabetes performance was seen in those practices with fewer competing demands: nonrural versus rural $(22.2 \%$ vs $15.1 \%$, respectively), and those not doing obstetrics versus those doing obstetrics $(20.3 \%$ vs $15.1 \%$, respectively), and for physicians versus associate providers $(\mathbf{1 8 . 8 \%}$ vs $\mathbf{1 5 . 1 \%}$, respectively). Higher patient satisfaction was observed in those dyads who were nonrural verus rural (96.6 vs 94.1\%), among those doing obstetrics $(96.0 \%$ vs $94.9 \%)$, and in physicians verus associate providers $(95.7 \%$ vs $93.2 \%)$. The number of years working with the same clinician was twice as high for RNs (6.63) and LPNs (6.57) than for MAs (3.29).

Conclusions: A higher level of education of the clinical associate seems to confer skills that enhance the care team's management of chronic illness such as diabetes. This could potentially decrease the practice burden on other team members while facilitating the team's objectives in meeting quality indicators. (J Am Board Fam Med 2012;25:854-861.)

Keywords: Nursing, Patient Care Team, Performance, Workload

The family medicine community in the United States is being confronted with a growing number

This article was externally peer reviewed.

Submitted 26 April 2011; revised 3 April 2012; accepted 23 April 2012.

From Franciscan Skemp Healthcare, Mayo Clinic Health System, La Crosse, WI (RAE, JRD); the Department of Environmental Toxicology, The Institute of Environmental and Human Health, Texas Tech University, Lubbock, TX (RAE, SBC); the Department of Internal Medicine, Mayo Clinic, Rochester, MN (PVT); and the Department of Family and Preventive Medicine, University of Oklahoma Health Sciences Center, Okalahoma City (JWM).

Funding: Richard Erickson has received support from the ARCS Foundation, the Helen Jones Foundation, and US Environmental Protection Agency,(EPA) STAR Fellowship Assistance Agreement no. FP91713201-0.

Conflict of interest: none declared.

Disclaimer: This article has not been formally reviewed by EPA. The views expressed in this presentation are solely those of Richard A. Erickson, and EPA does not endorse any products or commercial services mentioned in this presentation. of new challenges that are placing greater demands on a limited primary care workforce. As a specialty characterized by a broad scope of practice and continuity of care, ${ }^{1,2}$ we now are faced with an aging and increasingly diverse population during an era of economic constraints. Superimposed on these challenges are a new set of demands to meet performance indicators. ${ }^{3}$ The concept of the patientcentered medical home was developed, at least in part, in response to these demands. Central to the patient-centered medical home is the team approach. ${ }^{4-7}$ Although the team approach has been identified as necessary to address many of these problems effectively and efficiently, a working definition

Corresponding author: Rodney A. Erickson, MD, Mayo Clinic, 200 First Street SW, Rochester, MN 55905 (E-mail: hust.jean@mayo.edu). 
of the team-the collective group caring for the patient at a particular site- has been elusive, ${ }^{8-12}$ and the contributions of the various team members has not received the same level of scrutiny. ${ }^{11}$

Traditionally, the clinical component of the team has been the "doctor-nurse" dyad or, more appropriately, the clinician-clinical associate dyad. The dyad manages the majority of the clinical care, for example, medical decision making, office procedures, coordination of preventive services, and making phone calls about clinical issues. The care process for the clinician has been well studied. Stange et $\mathrm{al}^{13}$ eloquently described the physicianpatient encounter, whereas Baron ${ }^{14}$ and others ${ }^{15,16}$ recently have described the more global process required of primary care physicians. The involvement of the "office nurse," an essential and integral member of the primary health care team, has not been studied even though most practices utilize one or more per clinician. ${ }^{17}$

Nursing research has focused more often on inpatient care,${ }^{18,19}$ procedural care,${ }^{20,21}$ behavioral health, ${ }^{22}$ and advanced clinical nursing ${ }^{23,24}$ rather than primary care office-based nursing. In inpatient settings, the patient perception of care was improved by higher levels of nursing education, experience, time spent providing patient care, greater role clarity, and less role distraction. ${ }^{25,26}$

"Office nurses" or clinical associates (CAs) come from a variety of backgrounds, not just nursing. Most commonly they are trained as registered nurses (RNs), licensed practical nurses (LPNs), or medical assistants (MAs). Although each of these positions carries with it different job descriptions, licensure requirements, and responsibilities, ${ }^{26}$ often their roles are similar. Job responsibilities often include rooming patients, obtaining vital signs, obtaining a preliminary history, administering immunizations, and returning phone calls. In addition, the CA often serves as an important liaison between the patient and clinician, serving as both a buffer ("Mrs. Smith is really upset today") and patient advocate ("You promised to call Mr. Doe back this afternoon"). There are studies underway to clarify the relationship of CAs to others on the primary care team within ambulatory practices, ${ }^{27}$ but there is little in the literature to define their role or influence on team performance. Because the background of the CA may influence dyad and team performance, looking at the relationship between their background and dyad performance may help identify areas in which they impact the dyad and define their contribution. This study examines the CA's level of training, along with dyad tenure, clinician tenure, and clinician type, and how they relate to dyad performance in achieving diabetic metrics, patient satisfaction, and productivity.

\section{Methods}

\section{Practice Description}

The study took place in the family medicine practices of a Midwestern health system. The health system consisted of practices at 10 clinic sites, 1 secondary level hospital in a small city, and 2 rural critical access hospitals. Some clinicians were active staff members at one of 3 other rural critical access hospitals. The clinician dyads studied included family physicians, physician assistants, and nurse practitioners. Of the system's possible 58 family medicine clinicians employed during the study year, there were 55 dyads for which adequate data were available for at least one metric studied. From the 10 sites, 5 sites were affiliated with rural critical access hospitals (rural sites, each of which with was affiliated with a different hospital) and 5 sites had a primary hospital affiliation with the system's secondary-level hospital (nonrural). Those clinicians in rural practice had greater on-call, emergency department, and inpatient responsibilities than those in the other sites. Also, the rural sites had more unfilled clinician positions, with 4 of the 5 sites seeking to add one or more physicians, whereas there was only one unfilled position among the nonrural sites.

Two CA variables were studied: training and years working in the current dyad (tenure). CA training was divided into 3 categories: RN, LPN, and MA. Two clinician factors were compared: clinician type and years completed in practice with the health system. Clinician type was defined as either physician or associate provider (AP), including physician assistants and nurse practitioners. Other practice factors studied that were thought to influence performance included practice location (rural vs nonrural) and whether the clinician provided obstetric care. Clinician type and CA type were compared with the 3 practice factors (rural vs nonrural, inclusion or exclusion of obstetrics, and years of tenure). $\chi^{2}$ Analysis was used for site and inclusion of obstetrics. Years of tenure were compared using a standard 2-tailed $t$ test for clinicians and analysis of variance. 
Using an electronic diabetic registry, an annual diabetic performance summary was calculated at calendar year's end and reported by dyad. The diabetic quality indicator used was the percent of all patients with diabetes between the ages of 18 and 74 who met the goal in all 5 metrics defined by the health system at the time of the study: nontobacco use, daily aspirin use, blood pressure less than 130/80 mm Hg, low-density lipoprotein cholesterol $<100 \mathrm{mg} / \mathrm{dL}$, and glycohemoglobin $<7.0 \%$. Only those clinicians with $\geq 12$ months of tenure were included in this analysis. A multiple logistic regression was run to compare the effects of clinician type, CA type, site (rural vs urban), and inclusion of obstetric services on the percentage of patients achieving all 5 diabetic goals. An analysis of deviance was used to examine the deviances of the different coefficients. ${ }^{28}$ The regression coefficients were converted to odds ratios. A general linear model with a binomial distribution was used in $\mathrm{R}$ for this analysis. Tenure and diabetic performance were compared using a standard 2-tailed $t$ test and analysis of variance. Allied health staffing ratios measured the number of full-time equivalent CAs per full-time equivalent provider per site and were compared using linear regression.

Patient satisfaction was measured using a Press Ganey Patient Satisfaction Questionnaire. Press Ganey is national company that performs patient satisfaction surveys. Questionnaires were mailed out quarterly to 100 random patients for each clinician. If responses were $<30$ per 6 months for a given clinician, questionnaires were mailed to additional random patients for that clinician. The questionnaire included multiple factors regarding clinic visits; however, the clinician's score only relates to 11 questions that pertain directly to the clinician. Each question had 5 response options: very poor, poor, fair, good, and very good. A positive score represented those questions answered good or very good. Statistical analysis was performed as it was for diabetic metrics.

Productivity was calculated as a multiple of the mean for the clinicians in the study group using relative value units. Because physicians' mean productivity was approximately twice that of the APs, the productivity for physicians was based on the mean for physicians, and productivity for APs was based on the mean for APs. Only those with $>24$ months of tenure were included in productivity results. The effects of clinician type, CA type, site (rural vs nonrural), and inclusion of obstetrics, on provider productivity were examined using a multiple regression with a linear model in $\mathrm{R}$. Tenure and allied health staffing ratios were compared using linear regression. $P<0.05$ was taken as the level of statistical significance.

Staffing costs were not studied directly, but within this region average salaries for the $3 \mathrm{CA}$ positions were different, with LPNs earning, on average, approximately 1.3 times what MAs have earned, whereas RNs earned approximately 1.6 times as much.

\section{Results}

A description of the practices is shown in Table 1 . Of the 55 dyads studied, $78.2 \%$ (43 of 55) included a physician, $56.4 \%$ (31 of 55 ) were in rural sites, $36.4 \%$ (20 of 55 ) included obstetrics, $14.6 \%$ (8 of 55 ) included an $\mathrm{RN}, 44.6 \%$ (24 of 55) included an LPN, and $41.8 \%$ (23 of 55) included an MA. Comparing the dyads at rural sites with those at nonrural sites, more rural physicians did obstetrics (65.2\% vs $25 \% ; P=.0084)$, fewer rural dyads included RNs (3.2\% vs $29.2 \%)$, and more rural dyads included MAs (58.1\% vs $20.8 \%)(P=.0038)$. A higher percentage of dyads providing obstetrical care were rural than for the group as a whole $(75 \%$ vs $41.8 \% ; P=.083)$, but the obstetrical group did not differ by CA type. Clinician tenure did not differ, whereas RNs and LPNs had almost twice as much tenure as did the MAs (6.1 and 6.3 vs 3.1 years, respectively), but the groups did not reach statistical significance $(P=.0525)$.

Diabetic performance is shown in Table 2. For diabetes metrics, the group scored between the 45 th and 55 th percentile of practices for the Minnesota Community Health Measures ${ }^{29}$ during the period studied. The State of Minnesota annually collects data on all hospitals and providers in the state and publishes this information on a website labeled as the Minnesota Community Health Measures "to create a uniform approach to quality measurement." Although there was a difference between clinician types (physicians vs APs, $18.8 \%$ vs $15.1 \%$ ), site location (nonrural vs rural, $22.2 \%$ vs $15.1 \%$ ), and inclusion of obstetrics (exclude vs include, $20.3 \%$ vs $15.1 \%$ ). Overall dyads that included RNs tended to perform better on the diabetes quality indicators than the other 2 CA groups, and those with MAs performed worse. Clinician 
Table 1. Description of Practice by Location, Inclusion of Obstetrics, and Tenure ( $\mathrm{N}=55)$

\begin{tabular}{|c|c|c|c|c|c|}
\hline \multirow[b]{2}{*}{ Practice Variable } & \multicolumn{2}{|c|}{ Clinician Type } & \multicolumn{3}{|c|}{ Clinical Associate Type } \\
\hline & Physician & $\begin{array}{l}\text { Associate } \\
\text { Provider }\end{array}$ & $\begin{array}{l}\text { Registered } \\
\text { Nurse }\end{array}$ & Licensed Practical Nurse & $\begin{array}{l}\text { Medical } \\
\text { Assistant }\end{array}$ \\
\hline Total & $43(78.2 \%)$ & $12(11.8 \%)$ & $8(14.5 \%)$ & $24(43.6 \%)$ & $23(41.8 \%)$ \\
\hline Nonrural (n = 24) & $20(36.4 \%)$ & $4(63.6 \%)$ & $7(12.7 \%)$ & $12(21.5 \%)$ & $5(9.1 \%)$ \\
\hline Rural (n = 31) & $23(41.8 \%)$ & $8(14.5 \%)^{*}$ & $1(1.85)$ & $12(21.8 \%)$ & $18(32.7 \%)^{\dagger}$ \\
\hline Obstetrics $(\mathrm{n}=20)$ & $\begin{array}{l}20(36.4 \%) \\
\quad(15 \text { rural })\end{array}$ & $0^{\ddagger}$ & $\begin{array}{r}1(1.85 \%) \\
\quad(0 \text { rural })\end{array}$ & $\begin{aligned} & 12(21.5 \%) \\
&(8 \text { rural })\end{aligned}$ & $\begin{array}{l}7(12.5 \%)^{\S} \\
(7 \text { rural })\end{array}$ \\
\hline No obstetrics $(\mathrm{n}=35)$ & $23(41.8 \%)$ & $12(21.8 \%)$ & $7(12.7 \%)$ & $12(21.5 \%)$ & $16(29.1 \%)$ \\
\hline $\begin{array}{l}\text { Tenure, mean years } \pm \text { standard } \\
\text { deviation }\end{array}$ & $10.54 \pm 1.09$ & $10.64 \pm 2.31$ & $6.63 \pm 1.71$ & $6.57 \pm 1.20$ & $3.29 \pm 0.48$ \\
\hline
\end{tabular}

Values provided as $\mathrm{n}(\%)$ unless otherwise indicated.

${ }^{*}$ Clinician type by rural versus nonrural $(P=.416)$.

${ }^{\dagger}$ CA type by rural versus nonrural $(P=.0038)$.

${ }^{\ddagger}$ Among family medicine clinicians, only physicians do obstetrics.

${ }^{\S}$ Clinical associate type by obstetrics versus no obstetrics $(P=.120)$.

IT Tenure for physicians was years of practice within the system. Tenure for clinical associates was years paired with clinician. Tenure was not significant by clinician type or for clinical associate type $(P=.0525)$.

dyads in nonrural settings performed better than those in rural locations, and those who did not provide obstetric care performed better than those who provide this service. Longer clinician tenure $(P=.0319)$ but not dyad tenure (how long the team worked together) $(P=.261)$ was associated with better diabetes scores. Allied health staff-to-clinician ratio was not associated with better scores $(P=$ $.348)$.
Figure 1 shows the distribution of diabetic performance by CA type. As shown, not only did the $\mathrm{RN}$ group perform better collectively, but each dyad performed well, with all dyads scoring at least $20 \%$. Only $43 \%$ (10 of 13 ) of the LPN dyads and $16 \%$ (2 of 19 ) of the MA dyads scored at or above $20 \%$. Interestingly, the LPN dyads followed a bimodal distribution, with one cluster of teams performing at a level similar to $\mathrm{RN}$ dyad teams and the

Table 2. Diabetic Performance Metrics*

\begin{tabular}{|c|c|c|c|c|}
\hline Group & Patients per Group (n) & Achieving All 5 Metrics† (\%) & $\begin{array}{c}\text { Adjusted Odds Ratio } \\
\text { (95\% Confidence Interval) }\end{array}$ & $P$ \\
\hline Total & 2584 & 18.5 & & \\
\hline \multicolumn{5}{|c|}{ Clinical associate type } \\
\hline LPN & 1107 & 19.3 & 1.00 & \multirow[t]{3}{*}{$<.001$} \\
\hline MA & 1059 & 14.7 & $0.60(0.44-0.81)$ & \\
\hline $\mathrm{RN}$ & 418 & 27.8 & $1.37(1.01-1.84)$ & \\
\hline \multicolumn{5}{|l|}{ Clinician type } \\
\hline $\mathrm{AP}$ & 199 & 15.1 & 1.00 & \multirow[t]{2}{*}{.022} \\
\hline $\mathrm{MD} / \mathrm{DO}$ & 2385 & 18.8 & $2.23(1.23-4.41)$ & \\
\hline \multicolumn{5}{|l|}{ Site } \\
\hline Nonrural & 1230 & 22.2 & 1.00 & \multirow[t]{2}{*}{.78} \\
\hline Rural & 1354 & 15.1 & $1.14(0.82-1.57)$ & \\
\hline \multicolumn{5}{|c|}{ Inclusion of obstetrics } \\
\hline Not Included & 1697 & 20.3 & 1.00 & \multirow[t]{2}{*}{.011} \\
\hline Included & 887 & 15.1 & $0.69(0.51-0.92)$ & \\
\hline
\end{tabular}

*Performance of diabetes care is measured by the percent of patients who meet all 5 criteria of the Minnesota Community Measures: tobacco nonuse, systolic blood pressure $<130 \mathrm{mmHg}$ and diastolic $<80 \mathrm{mmHg}$, aspirin use if indicated, low-density lipoprotein cholesterol $<100 \mathrm{mg} / \mathrm{dL}$, and glycosylated hemoglobin $<7.0 \%$.

${ }^{\dagger}$ Percents are unadjusted.

$\mathrm{AP}$, associate provider; LPN, licensed practical nurse; MA, medical assistant; RN, registered nurse. 
Figure 1. Diabetes scores of dyads by nurse type. RN, registered nurse; LPN, licensed practical nurse; MA, medical assistant.

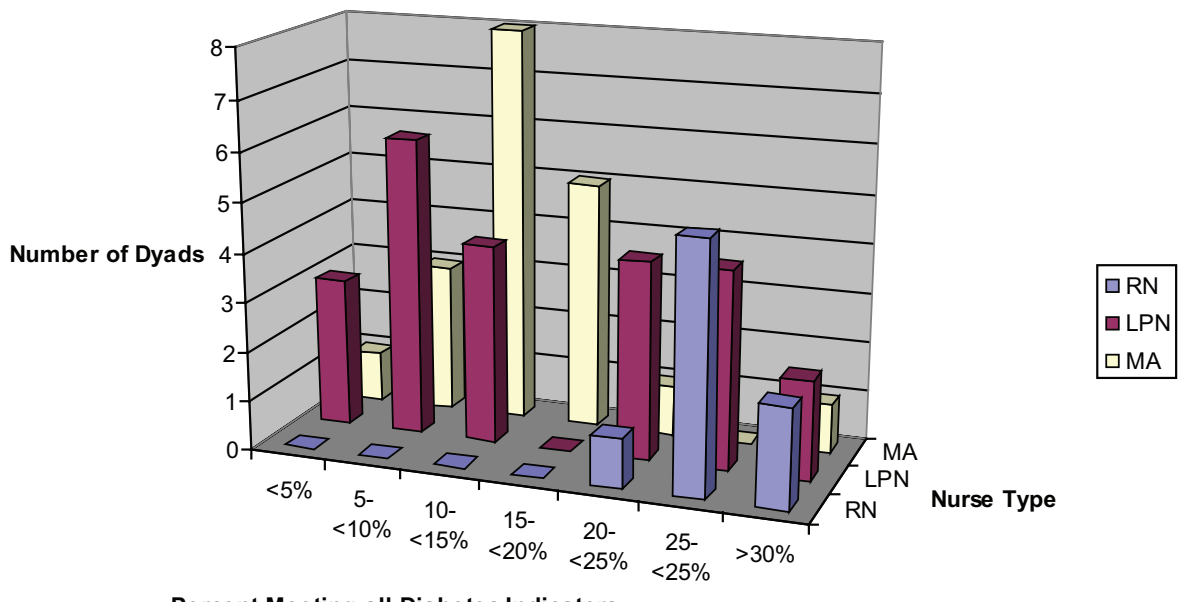

Percent Meeting all Diabetes Indicators

other performing at a lower level similar to most MA dyad teams, rather than as a single distribution intermediate to the 2 groups.

Patient satisfaction performance is shown in Table 3. The group's overall Press Ganey results scored between the 45 th and 55 th percentile on a Midwest regional basis. There were performance differences by clinician type, CA type, site, and whether the clinician provided obstetric services. Physicians received positive responses more often than associate providers (95.7 vs 93.2), as did RNs among the CAs (LPNs, 95.5; MAs, 94.6; RNs, 96.8), those in nonrural sites versus rural sites (96.6 vs 94.1), and those who provided obstetric care (96.0 vs 94.9). Clinician tenure, dyad tenure, and allied staffing ratios showed no effect on patient satisfaction.

For dyad productivity, the group again scored between the 45th and 55th percentile of the region's American Medical Group Association measurements, placing them near the mean for all 3 measures. Among the factors studied, CA type, site, provision of obstetric services, clinician tenure, dyad tenure, and allied staffing ratios, none were associated with differences in productivity. Those providing obstetrical services versus those who did

Table 3. Patient Satisfaction Scores

\begin{tabular}{|c|c|c|c|c|}
\hline Group & Responses (n) & Positive Responses* (\%) & $\begin{array}{l}\text { Adjusted Odds Ratio (95\% } \\
\text { Confidence Interval) }\end{array}$ & $P$ \\
\hline \multicolumn{5}{|l|}{ Associate type } \\
\hline LPN & 9210 & 95.5 & 1.00 & \multirow[t]{3}{*}{$<.001$} \\
\hline MA & 9509 & 94.6 & $0.65(0.53-0.80)$ & \\
\hline $\mathrm{RN}$ & 3735 & 96.8 & $1.14(0.88-1.48)$ & \\
\hline \multicolumn{5}{|l|}{ Provider type } \\
\hline $\mathrm{AP}$ & 4244 & 93.2 & 1.00 & \multirow[t]{2}{*}{$<.001$} \\
\hline MD/DO & 17850 & 95.7 & $1.75(1.41-2.17)$ & \\
\hline \multicolumn{5}{|l|}{ Site } \\
\hline Nonrural & 10355 & 96.6 & 1.00 & \multirow[t]{2}{*}{.0068} \\
\hline Rural & 11729 & 94.1 & $0.65(0.53-0.81)$ & \\
\hline \multicolumn{5}{|c|}{ Inclusion of obstetrics } \\
\hline Not included & 14254 & 94.9 & 1.00 & \multirow[t]{2}{*}{$<.001$} \\
\hline Included & 7810 & 96.0 & $1.56(1.27-1.93)$ & \\
\hline
\end{tabular}

*Percent positive responses are those that rated the care they received as "good" or "very good" and negative responses would be those rating their care as "fair," "poor," or "very poor."

$\mathrm{AP}$, associate provider; LPN, licensed practical nurse; MA, medical assistant; RN, registered nurse. 
not had higher productivity than all other groups (1.06 multiple of the mean [MOM] vs 0.97 MOM), but this did not reach statistical significance. Higher productivity by family physicians providing obstetric services is consistent with previous reports. $^{30,31}$

\section{Discussion}

In this study, those practices that had a clinician-RN dyad consistently performed better than the other dyads in meeting diabetic metrics and for patient satisfaction. Although the reasons for this could not be addressed in the study, there are several reasons why $\mathrm{RN}$ dyads may perform better. Internal differences between nurses and MAs have been identified; RNs possess "greater interpersonal connectedness," "greater autonomy," and a more patient-centered orientation. ${ }^{32,33} \mathrm{RNs}$ have more clinical training, and Watkins ${ }^{34}$ lists tenacity as a central component to the process of nurse's training. Carney et al ${ }^{35}$ and Carpiano et $\mathrm{al}^{36}$ have identified "tenacity," the acceptance of and adherence to guidelines, as an important component in teams for implementing clinical processes into practices. If tenacity is an important component for teams to successfully implement new clinical processes, whether it is something inherent or something acquired by those who continue their careers as RNs, it warrants further investigation. Within the dyads we studied, no formal role assignments for managing the diabetic registry had been given to the CAs by central leadership, so it is likely the RNs and some of the LPNs assumed greater ownership and follow through with diabetes management (tenacity) than the other dyads in these practices.

Along with tenacity, RNs may have an important role in relationship building and continuity of care. Sinsky et $\mathrm{al}^{17}$ has emphasized the importance of relationship building while using the office $\mathrm{RN}$ as a means for achieving high-quality, highly efficient care in chronic disease management. Clinician tenure, but not dyad tenure, was associated with better diabetic scores, though RNs and LPNs had, on average, longer tenure and higher scores than MAs. Nutting et $\mathrm{al}^{37}$ and Coleman et $\mathrm{al}^{38}$ also had mixed results; continuity is related to improved outcomes and satisfaction among older, more established patients with chronic disease but not among other groups; in this particular group, be- cause continuity and relationships with the clinician were valued more highly, it would follow that for the patients with diabetes, clinician and dyad stability should impact performance. As relationships are developed between CAs, clinicians, and patients, care, satisfaction, and staff retention may all benefit. ${ }^{39}$

Although the practices in this study showed overall better performance in meeting diabetic metrics by RN dyads, there were some MA dyads that performed exceptionally well. Solberg et al ${ }^{40}$ have reported exemplar practices that have successfully achieved diabetic management primarily using MAs in significant roles. More recently, including nonprofessional personnel on the team has been shown to improve the care of patients with diabetes. $^{41}$ The value of role clarity and system support allows different team members to assume a variety of nontraditional roles with good results. ${ }^{8,12,17}$

The lower scores on performance metrics by associate providers in relation to physicians differs from previous studies. ${ }^{8,12,17}$ In those studies, however, the associate providers often had defined roles to assist in chronic disease management. In these practices, the associate providers might have had various roles, often providing urgent care and managing "overflow." They also were more likely to be in rural, underserved practices, and none worked with RNs. All these factors would adversely affect both chronic disease management and patient satisfaction metrics.

Those practices with greater potential work intensity (rural practices and those providing obstetric services) did not perform as well on the diabetic metrics. The patient satisfaction results were somewhat mixed. Those providing obstetrics had slightly higher patient satisfaction scores in general; this is not surprising because generally the relationship between family physicians and obstetric patients tends to be positive. $^{30,31}$ However, those in rural practice had lower satisfaction scores. Of the rural practice sites, 4 of the 5 sites were understaffed for clinicians, and all required greater work intensity, including on-call and hospital responsibilities. Any of these factors, which create task saturation, may contribute to less access and more practice interruptions, leading to lower patient satisfaction. To compound these factors, those practices with greater work intensity were less likely to include an RN. Including more highly trained personnel at sites may lessen the work demands placed on the cli- 
nician. Increased workload not only impacts patient care and patient perception, but may also lead to decreased staff and provider satisfaction and ultimately burnout. ${ }^{42,43}$

Griffiths et $\mathrm{al}^{44}$ has shown that higher staffing ratios resulted in higher scores on quality metrics, something not observed in this study group. The practices studied here, however, were part of the same health system and may have had defined staffing ratios, making these ratios so uniform that there was too little variation to observe differences. The number of actual different sites also was small. Data on allied staff-patient encounters may have provided a better indicator, had it been available.

As health care moves to incorporate value along with quality, cost needs to be included in the equation. ${ }^{45}$ Costs and scarcity had driven the trend to hire MAs in primary care practices. Although RNs salaries were $160 \%$ and LPNs $130 \%$ of those of MAs in this area, the true cost-to-benefit ratio is not clear, particularly as demands on the primary care system increase. MAs had a higher turnover rate, which carries with it costs for recruiting and training along with the loss of institutional heritage and the disruption of relationships when someone leaves. MAs also must transfer more tasks and decision making to the clinician. Together these may all negate the salary differential.

The study has multiple limitations. This was a "case study" of only family physicians within one health care system. Because all clinicians were part of the same health care system, they have some shared values, and over time, shared collective experiences result in some degree of homogeneity and may not be representative of family physicians as a whole. The number of clinician dyads studied was small, especially the number of dyads with an $\mathrm{RN}$, and the nurse distribution between rural and nonrural practices was uneven. Even so, the group's performance on the items studied was typical for family physicians in the same geographic area. The RNs were more often part of a dyad with an experienced clinician and a dyad with more time spent together. Also, the data were collected at a time when there was no centralized effort by the system to address these specific issues beyond usual delivery of business and care. Although there was a large number of responses for patient satisfaction, the differences between groups (usually $1 \%$ to $2 \%$ ) was small, making comparisons difficult, but consistent patterns did emerge.
Teamwork is essential to meet the growing practice demands of Family Medicine, which involves an array of processes that are at times complimentary, competing, and in conflict with each other. Among these demands are expectations to meet performance metrics such as productivity, patient satisfaction, and clinical quality metrics. At the heart of the "team" are the team members. Our research suggests that RNs and LPNs already possess inherent skills that position them well to play key roles on the diabetes care team. Inclusion of the appropriate nurse type coupled with role clarity should improve team performance and decrease clinician workload. The added value of the appropriate team member includes the potential to improve the team's performance while decreasing clinician work load. The net result may be better care and higher satisfaction among patients, staff, and clinicians, which translates to better health and well-being of those people who place their trust in our care.

The authors acknowledge Jean Hust and Joanne Nordeen for their assistance with the literature review and preparation of the manuscript and Stephanie Hill, RN, for her assistance in data collection.

\section{References}

1. McWhinney IR. Teaching the principles of family medicine. Can Fam Physician 1981;27:801-4.

2. Phillips WR, Haynes DG. The domain of family practice: scope, role, and function. Fam Med 2001; 33:273-7.

3. Rosenthal MB, Landon BE, Normand SL, Frank RG, Epstein AM. Pay for performance in commercial HMOs. New Engl J Med 2006;355:1895-902.

4. Kellerman R, Kirk L. Principles of the patient-centered medical home. Am Fam Physician 2007;76:774-5.

5. Rosser WW, Colwill JM, Kasperski J, Wilson L. Progress of Ontario's Family Health Team model: a patient-centered medical home. Ann Fam Med 2011; 9:165-71.

6. Egger MJ, Day J, Scammon DL, Li Y, Wilson A, Magill MK. Correlation of the Care by Design primary care practice redesign model and the principles of the patient-centered medical home. J Am Board Fam Med 2012;25:216-23.

7. Ghorob A, Bodenheimer T. Share the care: building teams in primary care practices. J Am Board Fam Med 2012;25:143-5.

8. Casalino LP. Disease management and the organization of physician practice. JAMA 2005;293:485-8.

9. Feifer C, Nemeth L, Nietert PJ, et al. Different paths to high-quality care: three archetypes of top-performing practice sites. Ann Fam Med 2007;5:233-41.

10. Goh TT, Eccles MP. Team climate and quality of care in primary health care: a review of studies using 
the Team Climate Inventory in the United Kingdom. BMC Res Notes 2009;2:222.

11. Grumbach K, Bodenheimer T. Can health care teams improve primary care practice? JAMA 2004; 291:1246-51.

12. Tallia AF, Lanham HJ, McDaniel RR Jr, Crabtree BF. 7 characteristics of successful work relationships. Family Practice Management. 2006;13:47-50.

13. Stange KC, Zyzanski SJ, Jáen CR, et al. Illuminating the 'black box'. A description of 4454 patient visits to 138 family physicians. J Fam Pract 1998;46:377-89.

14. Baron RJ. What's keeping us so busy in primary care? A snapshot from one practice. New Engl J Med 2010;362:1632-6.

15. Gilchrist V, McCord G, Schrop SL, et al. Physician activities during time out of the examination room. Ann Fam Med 2005;3:494-9.

16. Pimlott N. Who has time for family medicine? Can Fam Physician 2008;54:14-6.

17. Sinsky CA, Sinsky TA, Althaus D, Tranel J, Thiltgen M. Practice profile. 'Core teams': nurse-physician partnerships provide patient-centered care at an Iowa practice. Health Aff (Millwood) 2010;29:966-8.

18. Attree M. Patients' and relatives' experiences and perspectives of 'good' and 'not so good' quality care. J Adv Nurs 2001;33:456-66.

19. Needleman J, Buerhaus P, Mattke S, Stewart M, Zelevinsky K. Nurse-staffing levels and the quality of care in hospitals. New Engl J Med 2002;346:1715-22.

20. Aiken LH, Clarke SP, Cheung RB, Sloane DM, Silber JH. Educational levels of hospital nurses and surgical patient mortality. JAMA 2003;290:1617-23.

21. Kovner C, Gergen PJ. Nurse staffing levels and adverse events following surgery in U.S. hospitals. Image J Nurs Sch 1998;30:315-21.

22. Campinha-Bacote J. Cultural competence in psychiatric mental health nursing. A conceptual model. Nurs Clin North Am 1994;29:1-8.

23. Irurita VF. Factors affecting the quality of nursing care: the patient's perspective. Int J Nurs Pract 1999;5:86-94.

24. Ohman-Strickland PA, Orzano AJ, Hudson SV, et al. Quality of diabetes care in family medicine practices: influence of nurse-practitioners and physician's assistants. Ann Fam Med 2008;6:14-22.

25. Blegen MA, Vaughn TE, Goode CJ. Nurse experience and education: effect on quality of care. J Nurs Adm 2001;31:33-9.

26. Riesenberg LA, Little BW, Wright V. Nonphysician medical educators: a literature review and job description resource. Acad Med 2009;84:1078-88.

27. Brown GL, Janiuk F, Lee L, Hannah S. Interprofessional care in primary health care settings: designing interventions to sustain cultural change and elevate clinical practice to curriculum expectations. Presented at the North American Primary Research Group Annual Meeting. Westin, Seattle, November 13-17, 2010.
28. Sokal RR, Rohlf FJ. Biometry. 4th edition. New York (NY): W. H. Freeman; 2012.

29. Minnesota Health Scores. 2011. Available from http://www.mnhealthscores.org/.

30. Cohen D, Coco A. Declining trends in the provision of prenatal care visits by family physicians. Ann Fam Med 2009;7:128-33.

31. Day KY, May TA, Hammer H. Family physicians and options for childbirth care. JAMA 2005;294:793, author reply 793 .

32. Mills AC, Blaesing SL. A lesson from the last nursing shortage: the influence of work values on career satisfaction with nursing. J Nurs Adm 2000;30:309-15.

33. Ohlen J, Segesten K. The professional identity of the nurse: concept analysis and development. J Adv Nurs 1998;28:720-7.

34. Watkins M. Tenacity-a central component in the preparation of clinical nurses. J Clin Nurs 1995;4:273-4.

35. Carney PA, Dietrich AJ, Keller A, Landgraf J, O'Connor GT. Tools, teamwork, and tenacity: an office system for cancer prevention. J Fam Pract 1992;35:388-94.

36. Carpiano RM, Flocke SA, Frank SH, Stange KC. Tools, teamwork, and tenacity: an examination of family practice office system influences on preventive service delivery. Prev Med 2003;36:131-40.

37. Nutting PA, Goodwin MA, Flocke SA, Zyzanski SJ, Stange KC. Continuity of primary care: to whom does it matter and when? Ann Fam Med 2003;1:149-55.

38. Coleman EA, Parry C, Chalmers S, Min SJ. The care transitions intervention: results of a randomized controlled trial. Arch Intern Med 2006;166:1822-8.

39. Lanham HJ, McDaniel RR Jr, Crabtree BF, et al. How improving practice relationships among clinicians and nonclinicians can improve quality in primary care. Jt Comm J Qual Patient Saf 2009;35:457-66.

40. Solberg LI, Hroscikoski MC, Sperl-Hillen JM, Harper PG, Crabtree BF. Transforming medical care: case study of an exemplary, small medical group. Ann Fam Med 2006;4:109-16.

41. Margolius D, Wong J, Goldman ML, Rouse-Iniguez J, Bodenheimer T. Delegating responsibility from clinicians to nonprofessional personnel: the example of hypertension control. J Am Board Fam Med 2012; 25:209-15.

42. Bowman MA, Neale AV. Family practice is a highly complex business. J Am Board Fam Med 2011;24:1-3.

43. Stange KC, Ferrer RL. The paradox of primary care. Ann Fam Med 2009;7:293-9.

44. Griffiths P, Murrells T, Maben J, Jones S, Ashworth M. Nurse staffing and quality of care in UK general practice: cross-sectional study using routinely collected data. Br J Gen Pract 2010;60:36-48.

45. Brook RH. The end of the quality improvement movement: long live improving value. JAMA 2010; 304:1831-2. 